\title{
Levantamento etnobotânico de plantas utilizadas como anti-hiperlipidêmicas e anorexígenas pela população de Nova Xavantina-MT, Brasil
}

\author{
Marcondes Alves B. da Silva, Laura Valdiane L. Melo, Reginaldo V. Ribeiro, \\ João Paulo M. de Souza, Joaquim Corsino S. Lima, Domingos Tabajara de O. Martins, \\ Regilane M. da Silva*
}

Área de Farmacologia, Departamento de Ciências Básicas em Saúde, Faculdade de Ciências Médicas, Universidade Federal de Mato Grosso, Av. Fernando Corrêa da Costa s/n, Coxipó, 78060-900 Cuiabá - MT, Brasil.

\begin{abstract}
RESUMO: O presente trabalho verificou a utilização de plantas medicinais encontradas no Cerrado mato-grossense para o tratamento de hiperlipidemias e obesidade. Entrevistas com 180 pessoas acima de 50 anos foram realizadas em Nova Xavantina-MT. O questionário abordou nome popular, parte utilizada, forma de preparo e uso das espécies citadas, além de informações gerais sobre o uso de plantas. As dez plantas mais citadas foram coletadas, identificadas e estudadas por meio de uma revisão bibliográfica. A maioria dos entrevistados $(95,6 \%)$ declarou utilizar plantas medicinais regularmente, sendo que $71,5 \%$ deles herdaram o conhecimento sobre plantas dos pais e avós e 94,20\% relataram aconselhar o uso aos mais jovens. Além disso, 93,6\% atestaram que as plantas são mais eficazes que os medicamentos de farmácia e 57\% consideraram forte o efeito das mesmas, ou seja, sempre resolvem o problema de saúde. Quanto aos efeitos adversos, $95,9 \%$ disseram nunca ter sentido após o uso de plantas. Dos entrevistados, $56,7 \%$ conheciam ou já haviam utilizado plantas medicinais no tratamento de hiperlipidemias e obesidade, sendo citadas 54 espécies medicinais diferentes pertencentes a 53 gêneros e 38 famílias, com destaque para Fabaceae (13\%). As dez plantas mais citadas foram: guatambu (Aspidosperma tomentosum Mart.), quinado-cerrado (Strychnos pseudoquina St. Hil.), ipê-roxo [Tabebuia impetiginosa (Mart. Ex DC.) Standl], embaúba (Cecropia pachystachya Trec.), calunga (Simaba sp.), pata-de-vaca [Bauhinia rufa (Bong.) Steud.], mangaba (Hancornia speciosa Gomez), batata-de-tiú [Jatropha elliptica (Pohl.) Muell. Arg.], folha-de-carne (Casearia sylvestris Sw.) e manacá (Spiranthera odoratissima A. St.-Hil.). A folha foi a parte mais utilizada (46\%) e o preparo das plantas ocorre principalmente por meio de infusão citado por $36,5 \%$ dos entrevistados. Apesar do uso popular destas plantas no combate as hiperlipidemias e obesidade, há necessidade de estudos fitoquímicos e farmacológicos que comprovem estas atividades, com vistas ao desenvolvimento de um fitoterápico.
\end{abstract}

Unitermos: Levantamento etnobotânico, Nova Xavantina, plantas medicinais, anti-hiperlipidêmicas, anorexígenas, Cerrado.

ABSTRACT: "Ethnobotanical survey of plants used as anti-hyperlipidemic and anorexigenic
by the population of Nova Xavantina-MT, Brazil". This study checked the use of medicinal
plants found in the Cerrado mato-grossense for the treatment of hyperlipidemia and obesity.
Interviews with 180 people over 50 years were held in Nova Xavantina-MT. The questionnaire
addressed popular name, part used, type of preparation and use of the species mentioned, beyond
general information about the use of plants. The ten plants most cited were collected, identified and
studied through a literature review. Most respondents ( $95.6 \%$ ) said using medicinal plants regularly,
while $71.5 \%$ of them inherited the knowledge of plants of parents and grandparents and $94.20 \%$
reported the use to advise youngsters. Furthermore, $93.6 \%$ attested that the plants are more effective
than the drugs from pharmacy and $57 \%$ considered the strong effect of the same, i.e., they always
solved health problems. Regarding adverse effects, $95.9 \%$ said they have never felt them after the
use of plants. Of the respondents, $56.7 \%$ knew or had used medicinal plants in the treatment of
hyperlipidemias and obesity, being cited 54 medicinal species belonging to 53 different genera and
38 families, with emphasis on Fabaceae (13\%). The ten most cited were: guatambu (Aspidosperma
tomentosum Mart.), quina-do-cerrado (Strychnos pseudoquina St. Hil.), ipê-roxo [Tabebuia
impetiginosa (Mart. Ex DC.) Standl], embaúba (Cecropia pachystachya Trec.), calunga (Simaba
sp.), pata-de-vaca [Bauhinia rufa (Bong.) Steud.], mangaba (Hancornia speciosa Gomez), batata-
de-tiú [Jatropha elliptica (Pohl.) Muell. Arg.], folha-de-carne (Casearia sylvestris Sw.) and manacá 
(Spiranthera odoratissima A. St.-Hil.). The leaf was the most used (46\%) and the preparation of the plants occurs mainly through the infusion cited by $36,5 \%$ of respondents. Despite the popular use of these plants for treatment of obesity and hyperlipidemia, further chemical and pharmacological studies are required to demonstrate these activities, in order to develop a phytotherapic product.

Keywords: Ethnobotanical survey, Nova Xavantina, medicinal plants, anti-hyperlipidemic plants, anoretic plants, Cerrado.

\section{INTRODUÇÃO}

Doenças cardiovasculares (DCV) como: acidente vascular cerebral, angina, infarto do miocárdio e doença vascular periférica, representam a maior causa de morte em países ocidentais. Originam-se principalmente de complicações da aterosclerose, síndrome caracterizada pelo acúmulo de lipídeos e células inflamatórias nas paredes internas de artérias e arteríolas importantes do organismo, gerando a placa aterosclerótica que reduz a perfusão sanguínea de órgãos vitais. Uma causa essencial da aterosclerose é a elevação dos níveis plasmáticos de colesterol e/ou triglicérides, distúrbios metabólicos conhecidos como hiperlipidemias (Clayton \& Stock, 2006).

Do ponto de vista clínico, as hiperlipidemias podem ser divididas em: 1. hipercolesterolemia: níveis plasmáticos elevados de colesterol total e lipoproteínas de densidade baixa (LDL); 2. hipertrigliceridemia: concentrações plasmáticas elevadas de triacilglicérides e 3. hiperlipidemia mista: complexo perfil lipídico que pode consistir em níveis elevados de colesterol total, LDL e triacilglicérides. A presença de níveis diminuídos de lipoproteínas de densidade alta (HDL), também constitui fator de risco independente para o desenvolvimento de aterosclerose e DCV (Golan et al., 2009).

São reconhecidas numerosas causas de hiperlipidemias, tais como fatores essencialmente genéticos ou interações menos definidas entre genes e ambiente, e fatores secundários, como o consumo excessivo de álcool, diabetesmelitotipoII, hipotireoidismo, dietaricaemgordura saturada e colesterol, estresse, gravidez, medicamentos, dentre outros (Golan et al., 2009). A obesidade, doença caracterizada pelo excesso de gordura corporal, é comumente associada às hiperlipidemias, principalmente hipertrigliceridemia e decréscimo dos níveis plasmáticos de HDL. Esta associação, sem dúvida desempenha papel importante no desenvolvimento de aterosclerose e DCV em indivíduos obesos (Howard et al., 2003).

A utilização de fármacos anorexígenos como a sibutramina e o orlistate, representa a tentativa de controlar o apetite e, com isso, reduzir a obesidade e suas complicações. Contudo, a efetividade da terapia com estes agentes depende de modificações na dieta e prática regular de exercícios físicos (Rang et al., 2007). Quanto à hiperlipidemia, a redução do peso propicia principalmente o aumento do HDL e a redução do triacilglicérides plasmáticos. Além disso, o uso de fármacos hipolipidemiantes, como as estatinas e os fibratos, também auxiliam na melhora do perfil lipídico (Sociedade Brasileira de Cardiologia, 2002).

Contudo, estudos a respeito da terapia com fármacos hipolipemiantes indicam alguns fatores que contribuem para a não adesão ao tratamento, tais como a falta de orientação sobre o uso do medicamento, responsável por cerca de $31 \%$ das irregularidades do tratamento hipolipemiante e, sobretudo, o custo alto da terapia contínua com os medicamentos prescritos, citado como o principal responsável pela irregularidade no tratamento (Mansur et al., 2001; Vacanti et al., 2005; Krause et al., 2008).

Neste contexto, crescem em importância estudos para o desenvolvimento de novas alternativas terapêuticas eficazes e acessíveis às populações de baixa renda, sendo as plantas medicinais aliadas extremamente úteis, pois fornecem extratos e compostos químicos isolados, cujas capacidades anorexígena e hipolipidêmica vêm sendo demonstradas em inúmeros trabalhos científicos de várias partes do mundo (Kidwai \& Upreti, 1993; Jorge et al., 1998; Heerden et al., 2007; Lei et al., 2007; Xie et al., 2007; Bahramikia \& Yazdanparast, 2008; Cardozo et al., 2008; Harnafi et al., 2008; Murray et al., 2008; Ming et al., 2009).

No entanto, a pesquisa de novas substâncias oriundas de plantas necessita da junção de algumas áreas essenciais, como a fitoquímica, que trabalha com a purificação, o isolamento e a caracterização de princípios ativos, a farmacologia, que estuda os efeitos farmacológicos de extratos e dos constituintes químicos isolados, e a etnobotânica, que busca informações a partir do conhecimento de diferentes povos e etnias (Albuquerque \& Hanazaki, 2006). Esta última constitui a base da maioria dos estudos fitoquímicos e farmacológicos, pois auxilia na seleção de espécies medicinais de acordo com sua utilização por grupos populacionais específicos, enfatizando a busca pelo conhecimento transmitido de geração em geração a respeito de seus recursos naturais e a aplicação destes em seus sistemas de saúde e doença, ou seja, a etnobotânica se ocupa da inter-relação entre pessoas e plantas (Albuquerque \& Hanazaki, 2006). Com isso, Mato Grosso apresenta-se como uma área de extrema importância para o desenvolvimento de estudos etnobotânicos, pois possui cerca de 422125 $\mathrm{km}^{2}$ de Cerrado brasileiro (Pereira et al., 1997), sendo, portanto, o Estado que detém a maior parte deste bioma que representa uma das maiores riquezas naturais em espécies vegetais, incluindo as de uso medicinal (Sano 
\& Almeida, 1998). Entretanto, essa riqueza permanece ainda, em grande parte, desconhecida do ponto de vista científico, além disso, o extrativismo e o desmatamento descontrolados representam uma séria ameaça à biodiversidade desta região (Vieira \& Martins, 1996).

Portanto, estudos científicos em áreas de Cerrado do Estado de Mato Grosso são cada vez mais necessários, principalmente relacionados a síndromes metabólicas de grande importância clínica, como é o caso da obesidade e das hiperlipidemias. Considerando esse fato, o presente estudo teve como objetivos: Identificar plantas medicinais encontradas no Cerrado matogrossense, utilizadas e recomendadas por moradores de Nova Xavantina-MT para o tratamento concomitante das hiperlipidemias e da obesidade (anorexígenas); e pesquisar na literatura científica informações sobre usos populares, características químicas, farmacológicas e toxicológicas referentes às plantas mais citadas pelos entrevistados.

\section{MATERIAL E MÉTODOS}

O presente estudo etnobotânico, observacional de corte transversal, foi realizado entre os meses de outubro 2007 e junho de 2008 na cidade de Nova Xavantina, localizada na região leste do Estado de Mato Grosso, às margens do rio das Mortes e distante aproximadamente 650 km de Cuiabá. Segundo o IBGE, a população estimada em 2007 foi de 18670 habitantes, distribuída sob densidade populacional de $3,3 \mathrm{hab} / \mathrm{km}^{2}$. O ponto central da localidade está entre as coordenadas geográficas $14^{\circ} 41^{\prime} 09^{\prime \prime}$ de latitude sul e $52^{\circ} 20^{\prime} 09^{\prime \prime}$ de longitude oeste (Figura 1).

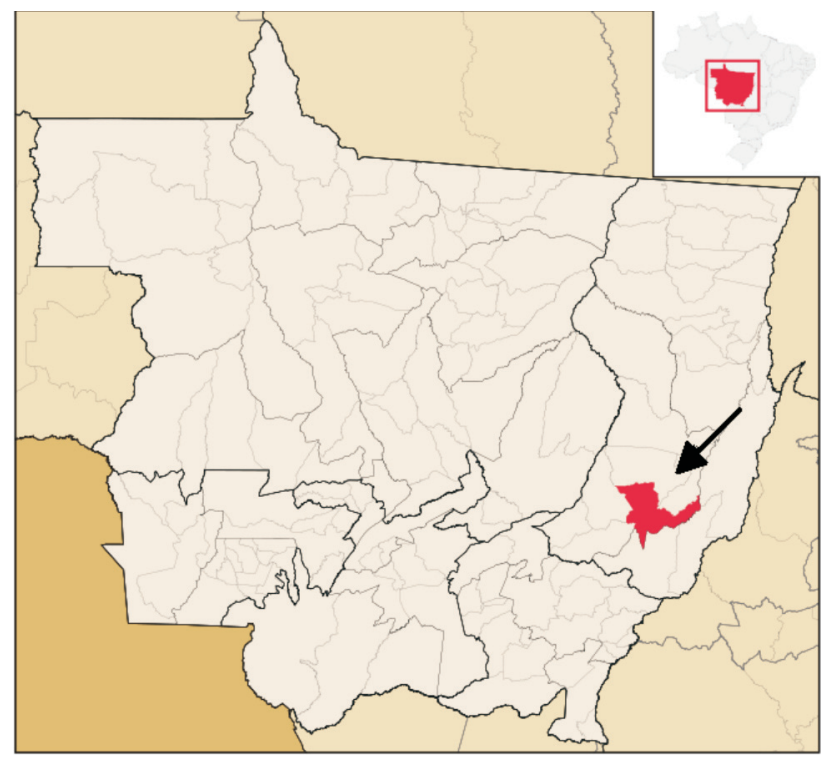

Figura 1. Mapa do estado de Mato Grosso mostrando a localização geográfica de Nova Xavantina (seta) (Fonte: pt.wikipedia).

Destaca-se na região a pecuária intensiva, com sistema de cria, recria e corte. O clima é tropical quente e sub-úmido, com quatro meses de seca, de maio a agosto e precipitação média anual de 1750 $\mathrm{mm}$, com intensidade máxima em dezembro, janeiro e fevereiro. A temperatura média anual é de $24{ }^{\circ} \mathrm{C}$, podendo atingir até $38{ }^{\circ} \mathrm{C}$ em determinadas épocas do ano (Prefeitura Municipal de Nova Xavantina, 2008).

A cidade está inserida no bioma Cerrado, destacando-se o Cerrado stricto sensu, uma fitofisionomia savânica que se caracteriza pela coexistência de um estrato arbóreo-arbustivo e de um herbáceo-graminoso, ambos bem desenvolvidos. O Parque do Bacaba, situado no perímetro urbano do município, possui aproximadamente 500 ha com vegetação de Cerrado stricto sensu (Cerrado denso, Cerrado típico, Cerrado ralo e Cerrado rupestre), cerradão, mata de galeria e vereda (Silva et al., 2007; Ribeiro et al., 2008).

Foram convidadas a participar da pesquisa 180 pessoas com idades entre 50 e 90 anos. Este intervalo de idade foi escolhido devido ao maior conhecimento de plantas medicinais que estas pessoas teoricamente possuem em relação aos mais jovens. Outros trabalhos da área reconhecem a importância das informações sobre plantas provenientes de pessoas idosas (Guarim Neto, 1987; Matos, 1989). O cálculo do tamanho da amostra utilizou a proporção de habitantes nessa faixa etária constatada pelo censo IBGE do ano 2000 (IBGE, 2004).

$\mathrm{O}$ tamanho da amostra (n) foi calculada pela fórmula:

$$
\mathrm{n}=\frac{\mathrm{N} p(1-\mathrm{p})}{(\mathrm{N}-1)\left(\mathrm{d} / \mathrm{Z}_{\alpha_{2}}\right)^{2}+\mathrm{p}(1-\mathrm{p})}
$$

Onde: $\mathrm{n}=$ tamanho da amostra, $\mathrm{N}=$ População estudada, $\mathrm{p}=$ proporção populacional, $\mathrm{d}=$ erro estimado pelo pesquisador e $Z_{\alpha / 2}=$ constante da tabela de distribuição normal.

Para a coleta dos dados foi utilizado um questionário semi-estruturado (Anexo 1), composto de perguntas fechadas e abertas distribuídas em três partes distintas: a primeira referente aos dados pessoais dos moradores (idade, sexo, origem e escolaridade); a segunda forneceuinformações sobre ousogeral de plantas medicinais pelos entrevistados (freqüência e influência do uso, efeito terapêutico e adverso etc.), além disso, ainda verificou se o perfil lipídico do entrevistado estava alterado no último exame realizado; a terceira parte, constou de dados sobre as plantas citadas como anorexígenas e hipolipidêmicas (parte utilizada, modo de preparo, coleta e posologia).

As perguntas sobre o uso terapêutico das plantas foram estritamente relacionadas ao tratamento simultâneo de hiperlipidemias e obesidade, pois essas duas síndromes metabólicas estão comumente relacionadas entre si. Durante as entrevistas, para facilitar o entendimento dos moradores a respeito do tema, os entrevistadores utilizaram alguns termos populares, tais como: gordura no sangue ou sangue gorduroso, colesterol alto, obesidade ou gordura no corpo, emagrecimento ou diminuição do peso e tirar a fome ou a vontade de comer. 
As entrevistas foram realizadas no Clube da Terceira Idade, uma entidade mantida pela Prefeitura Municipal de Nova Xavantina-MT que reúne, diariamente, praticamente todos os idosos da cidade, fornecendo atividades de recreação e aprendizagem. Todos os entrevistados foram informados quanto ao objetivo e a metodologia da pesquisa e aqueles que concordaram em participar assinaram o termo de consentimento livre e esclarecido (TCLE), conforme determinação da Resolução CNS (Conselho Nacional de Saúde) 196/96 (Ministério da Saúde, 1996).

Após as entrevistas, procedeu-se a coleta do material botânico das dez plantas mais citadas pelos entrevistados. Idosos que se disseram experientes no conhecimento das plantas, auxiliaram na indicação do local de coleta e na retirada das partes reprodutivas que foram acondicionadas em exsicatas. Todas as dez plantas coletadas foram encontradas em Cerrado stricto sensu próximo à cidade, inclusive com características de desmatamento. Os nomes botânicos das demais plantas citadas pelos entrevistados foram atribuídos mediante pesquisas em bases de dados botânicas e consultas em literatura sobre a flora do Estado de Mato Grosso referente a diversos autores (Amorozo, 2002; Felfili et al., 2002; Guarim Neto \& Morais, 2003; Borba \& Macedo, 2006; Guarim Neto, 2006; Jesus et al., 2009).

As exsicatas preparadas foram depositadas no Herbário do Instituto Universitário do Araguaia, um Campus da Universidade Federal de Mato Grosso localizado na cidade de Pontal do Araguaia, distante $150 \mathrm{~km}$ de Nova Xavantina. Posteriormente, uma pesquisa bibliográfica a respeito das espécies coletadas, seus gêneros e famílias, foi realizada em diversas bases científicas, como a Biblioteca Regional de Medicina da Unifesp (Bireme) e periódicos disponíveis no portal da Coordenação de Aperfeiçoamento de Pessoal de Nível Superior (CAPES), com o intuito de obter informações sobre o uso popular, a composição química, a atividade farmacológica e a toxicidade. $\mathrm{O}$ projeto inicial foi submetido à análise do Comitê de Ética em Pesquisa com Seres Humanos do Hospital Universitário Júlio Muller/UFMT, sendo aprovado sob o protocolo $\mathrm{N}^{\circ}$ 418/CEP-HUJM/07. A autorização para coleta de material botânico foi fornecida pelo Sistema de Autorização e Informação em Biodiversidade (SISBIO) do Instituto Brasileiro do Meio Ambiente e dos Recursos Naturais Renováveis (IBAMA), um órgão do Ministério do Meio Ambiente do Brasil, sendo o comprovante de autorização registrado sob o número 2354534. Para tabulação e análises dos dados, utilizou-se o programa estatístico Epi Info versão 6.04.

\section{RESULTADOS E DISCUSSÃO}

Analisando os resultados apresentados na Figura 2, verifica-se que a maioria da população pesquisada $(98,3 \%)$ residia na zona urbana e o sexo feminino representou a maior parcela, com $59,4 \%$. Nota-se que a origem urbana dos entrevistados é semelhante aos dados obtidos pelo censo populacional do ano de 2000 , quando a população urbana da cidade foi de $81,3 \%$. Por outro lado, nesse mesmo censo, o sexo masculino representou a maior porcentagem $(51,5 \%)$, ao contrário do que ocorreu neste trabalho (Seplan, 2007), podendo-se dever à faixa etária selecionada ou ao local aonde realizou-se a pesquisa.

Quanto ao grau de escolaridade, 61,7\% disseram ter apenas o ensino fundamental completo, $27,2 \%$ se consideraram analfabetos e apenas $1,7 \%$ tinham curso superior completo. No que diz respeito a idade, os entrevistados possuíam entre 50 e 90 anos. Guarim Neto (1987) destaca que as pessoas mais idosas são detentoras de preciosas informações sobre o uso de plantas e que estas podem subsidiar o conhecimento do potencial terapêutico da flora mato-grossense e nacional.

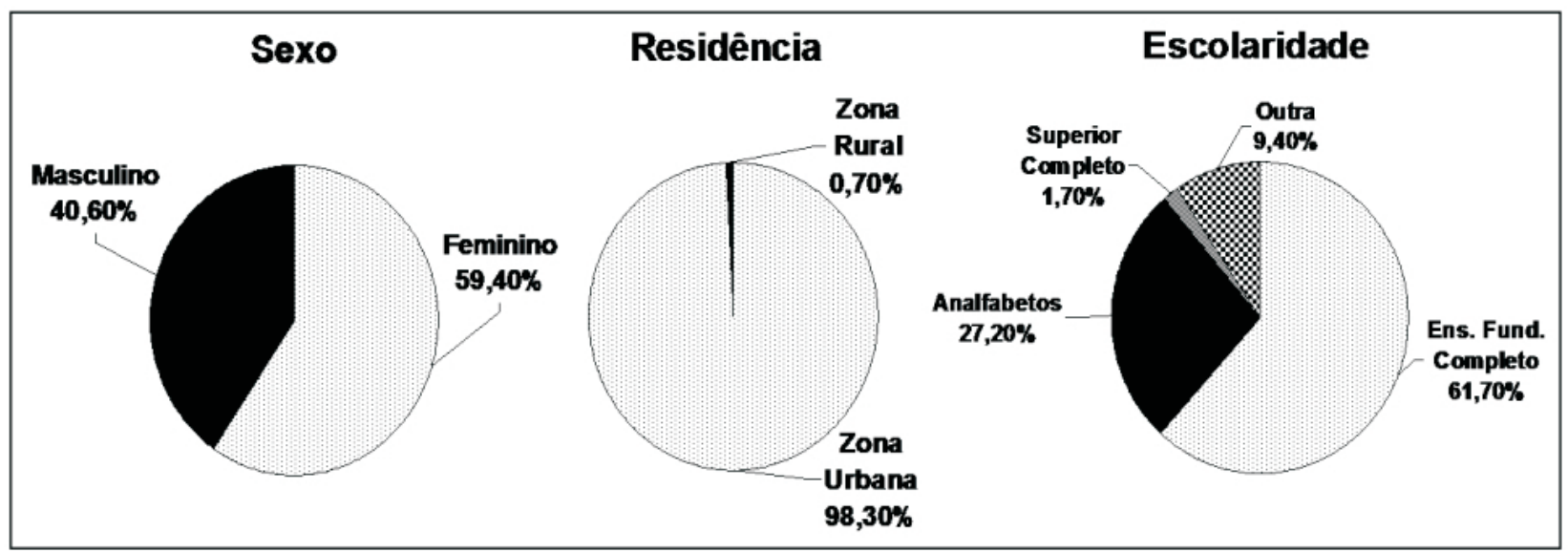

Figura 2. Características sócio-demográficas da amostra populacional entrevistada em Nova Xavantina-MT. 
Características semelhantes também foram verificadas em outros estudos etnobotânicos, tais como o estudo de Borba \& Macedo (2006), onde a maioria dos entrevistados era do sexo feminino e tinham idade acima de 50 anos, $45 \%$ eram não alfabetizados e apenas um deles tinha ensino superior completo. Em outra abordagem etnobotânica realizada por Pereira et al. (2005), 61\% dos participantes eram analfabetos ou não haviam concluído o ensino fundamental, além disso, estes autores verificaram que o uso de plantas medicinais é significativamente maior em pessoas com idade acima de 50 anos.

O questionário aplicado neste estudo continha, além de perguntas específicas a respeito do conhecimento de plantas com atividade hipolipidêmica e anorexígena, outras questões referentes ao uso geral de plantas medicinais pelo entrevistado, como demonstrado na Figura 3, onde $95,6 \%$ utilizavam plantas regularmente para tratar diversos problemas de saúde, ou seja, fizeram uso pelo menos uma vez nos últimos doze meses que antecederam à entrevista. Porcentagem alta, mas comum em muitos estudos etnobotânicos realizados em centros urbanos, como em Juiz deFora-MG, local em que Barreto etal.(2006)entrevistaram 75 idosos e notaram que $96 \%$ utilizavam plantas como prática terapêutica cotidiana, porcentagem igual também foi obtida por Negrelle et al. (2007), em Cascavel-PR.

A confiança no poder curativo das plantas é tão grande, que $93,6 \%$ dos entrevistados as consideraram mais eficientes que os medicamentos sintéticos, justificando o fato de muitos não procurarem os serviços de saúde ao sentirem algum sintoma importante. Monteles \& Pinheiro (2007), também notaram essa preferência por "remédios caseiros" em $66,7 \%$ de seus informantes, sendo que outros $25,7 \%$ usavam plantas medicinais concomitantemente com medicamentos industrializados e de maneira contínua. Os entrevistados por Borba \& Macedo (2006) afirmaram que a primeira opção de medicamento para qualquer "perturbação de saúde" em geral seria o remédio caseiro, depois procurar o médico.

Quanto ao efeito terapêutico das plantas, apenas $0,6 \%$ consideraram fraco (raramente fazem efeito), $42,4 \%$ consideraram o efeito moderado (efeito considerável em muitas situações) e $57 \%$ acham o efeito das plantas forte (sempre fazem efeito e resolvem o problema de saúde). Esses resultados, de certo modo, sugerem boa efetividade das plantas na resolução dos problemas de saúde dos moradores entrevistados. Relacionando a ocorrência de efeitos adversos com o uso de plantas medicinais, notou-se que a maioria $(95,9 \%)$ relatou nunca ter sentido efeitos tóxicos ao utilizar os "remédios caseiros", os demais disseram já ter sentido desconforto estomacal, tonturas e sonolência. Essa porcentagem representa a idéia errada dos entrevistados, de que as plantas medicinais seriam isentas de qualquer efeito tóxico ao organismo. Contudo, em torno de 5\% dos entrevistados até alertaram sobre o potencial tóxico de algumas espécies citadas, indicando o uso apenas em pequenas quantidades. No levantamento etnobotânico realizado por Marçal et al. (2003), em Goioerê - PR, também foi constatada pequena porcentagem de efeitos adversos com o uso de plantas pelos entrevistados, apenas $4 \%$, os quais citaram a ocorrência de tonturas, náuseas e irritação dérmica. Barreto et al. (2006), verificaram que $93 \%$ de seus entrevistados desconheciam contra-indicações, toxicologia, interações ou efeitos adversos das plantas que citaram.

Apesar do baixo índice de efeitos adversos já relatados em estudos anteriores, sabe-se que muitas plantas medicinais apresentam substâncias que podem desencadear reações tóxicas, exigindo um rigoroso controle de qualidade desde o cultivo, coleta, extração de seus constituintes, até a elaboração final do fitoterápico (Turolla \& Nascimento, 2006).

$\mathrm{O}$ conhecimento passado de geração em geração constitui importante fator para a disseminação do uso popular das plantas medicinais, tendo sido a principal fonte de informação utilizada pelos entrevistados em Nova Xavantina $(71,5 \%)$, os demais disseram que a influência maior para a utilização de plantas foi proveniente de amigos, vizinhos, ou mesmo de livros sobre o assunto. Tal fato, também foi verificado por inúmeros estudos na área de etnobotânica (Marçal et al., 2003; Pereira et al., 2005; Barreto et al., 2006; Borba \& Macedo, 2006; Vendruscolo \& Mentz, 2006).

Os entrevistados em Nova Xavantina também relataram indicar o uso de plantas aos mais jovens (94,2\%), contudo, disseram encontrar dificuldades em passar o conhecimento as futuras gerações devido à falta de interesse dos filhos e netos. De acordo com Amorozo (2002), o desenvolvimento de novas opções de cuidados com a saúde causa certa desvalorização da cultura local, à qual os jovens são o grupo mais sensível, reforçando a tendência à perda ou abandono das práticas tradicionais.

O fato de $20,1 \%$ dos informantes terem relatado níveis plasmáticos de colesterol total e triacilglicérides acima dos valores normais no último exame realizado (Figura 4) é preocupante, visto que taxas elevadas desses lipídeos, principalmente nesta faixa etária, são comumente relacionadas a aumento da prevalência de doenças cardiovasculares (Moriguchi \& Vieira, 2006). Além disso, $72,4 \%$ disseram não ter conhecimento de seu perfil lipídico ou não realizar exames periódicos, ou seja, pode estar instalado um quadro de prevalência oculta que merece atenção especial, visto que a placa aterosclerótica se instala de forma lenta, progressiva e sem sintomatologia aparente.

Mais da metade dos entrevistados $(56,7 \%)$, já havia utilizado ou conhecia plantas medicinais comumente encontradas no Cerrado da região e eficazes na redução de lipídeos plasmáticos e como anorexígenas. Este percentual reflete bom conhecimento dos entrevistados a respeito dos recursos utilizados pela medicina popular para o tratamento das hiperlipidemias e obesidade. Cada pessoa entrevistada podia citar quantas plantas 
quisesse, sendo que tais citações originaram 54 plantas medicinais diferentes, as quais estão listadas na Tabela 1.

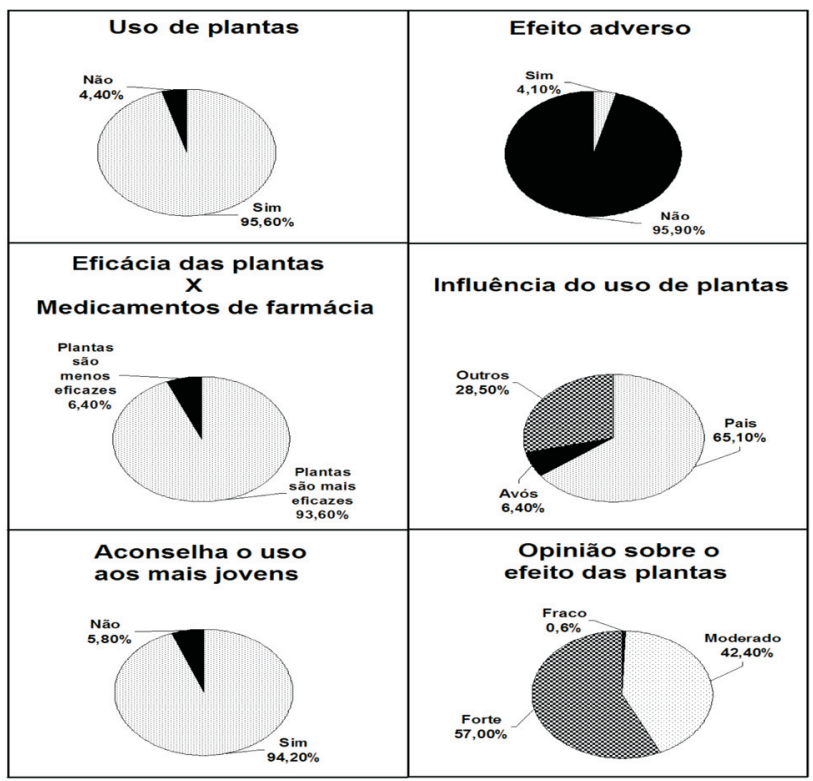

Figura 3. Características do uso de plantas pelos entrevistados de Nova Xavantina-MT.

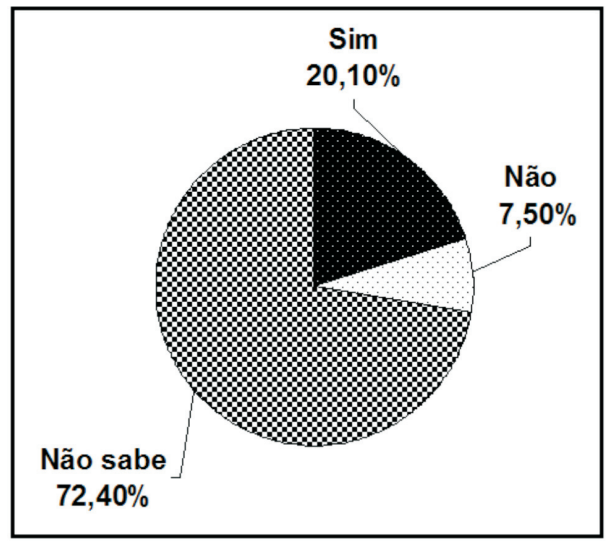

Figura 4. Respostas dos entrevistados de Nova Xavantina-MT, quanto ao perfil lipídico alterado no último exame realizado.

Dentre as 54 plantas apresentadas, as dez mais citadas foram: guatambu (Aspidosperma tomentosum Mart.), 19,2\%; quina-do-cerrado (Strychnos pseudoquina St. Hil.), 7,2\%; ipê-roxo (Tabebuia impetiginosa (Mart. Ex DC.) Standl), 5,6\%; embaúba (Cecropia pachystachya Trec.), 4,8\%; calunga (Simaba sp.), 4,0\%; pata-de-vaca (Bauhinia rufa (Bong.) Steud.), 4,0\%; mangaba (Hancornia speciosa Gomez), 3,2\%; batata-de-tiú (Jatropha elliptica (Pohl.) Muell. Arg.), 2,4\%; folha-de-carne (Casearia sylvestris Sw.), 2,4\% e manacá (Spiranthera odoratissima A. St.-Hil.), 2,4\%, as quais foram coletadas e identificadas botanicamente. Estas plantas representaram expressivos $55,2 \%$ de todas as citações, sugerindo ampla disseminação do uso das mesmas no tratamento de hiperlipidemias e obesidade em Nova Xavantina. A planta denominada como calunga (Simaba sp.) foi identificada apenas em nível de gênero, pois o período irregular de chuvas pode ter alterado sua floração na região, o que impossibilitou a coleta de sua parte reprodutiva.

As espécies e famílias atribuídas às demais plantas da Tabela 1, foram nominadas, correlacionando os nomes populares fornecidos pelos entrevistados, com informações obtidas mediante pesquisa bibliográfica em diversas bases de dados e artigos científicos relacionados à flora de Mato Grosso. Com isso, a identificação botânica e as pesquisas bibliográficas possibilitaram a listagem de 53 gêneros botânicos diferentes, pertencentes a 38 famílias. Dentre as famílias listadas, Fabaceae apresentou o maior número de espécies (13\%), seguida das famílias Euphorbiaceae e Myrtaceae, ambas com 5,5\%. A família Fabaceae é de grande ocorrência em MT, sendo também a mais citada no levantamento realizado por Jesus et al. (2009) em Nossa Senhora do Livramento-MT.

A Tabela 1 também apresenta a quantidade de pessoas que utilizaram a planta citada e perceberam redução dos níveis de colesterol plasmático. Esses dados sugerem a efetividade destas plantas em reduzir a "gordura do sangue" e/ou reduzirem o peso corporal, propriedades que abrem diversas possibilidades de pesquisas químico-farmacológicas para comprovação científica destas atividades, o que poderia até mesmo levar ao desenvolvimento de um medicamento fitoterápico mais barato e mais efetivo no tratamento das hiperlipidemias/obesidade. Entretanto, percebe-se que muitas pessoas citaram plantas porque ouviram falar a respeito de sua capacidade terapêutica, e não porque já haviam utilizado como hipolipidêmica e anorexígena.

O guatambu (Aspidosperma tomentosum Mart.) foi a planta com maior número de citações (19,2\%). Alguns dos entrevistados alertaram quanto aos efeitos tóxicos da mesma, indicando o uso em pequenas quantidades e poucas vezes ao dia. O extrato etanólico desta planta foi ativo em formas tripomastigotas de Trypanosoma cruzi in vitro (Oliveira et al., 2001). Além disso, atividades antinociceptiva (Epifânio et al., 2007) e antineoplásica (Kohn et al., 2006) também foram atribuídas a extratos e frações de Aspidosperma tomentosum. No entanto, nenhuma citação da atividade hipolipidêmica e anorexígena dessa espécie foi encontrada em outros trabalhos. Por outro lado, outra espécie do mesmo gênero, Aspidosperma subincanum, foi ativo em modelo de hiperlipidemia induzida por Triton WR 1339 em camundongos, reduzindo o nível de triglicérides sérico em $41 \%$ quando comparado aos animais normais (Silva, 2009). Esta mesma espécie demonstrou ter toxicidade aguda em estudo realizado por Santos (2005). Aspidosperma subincanum também foi indicada para problemas associados ao aparelho digestivo (Monteles \& Pinheiro, 2007), e para o tratamento tanto do diabetes e da hipercolesterolemia (Tresvenzol et al., 1997). Outra planta do gênero Aspidosperma, a Aspidosperma macrocarpon, obteve potente atividade in 
Tabela 1. Plantas medicinais com atividade anorexígena e hipolipidêmica citadas pelos entrevistados residentes em Nova Xavantina - MT.

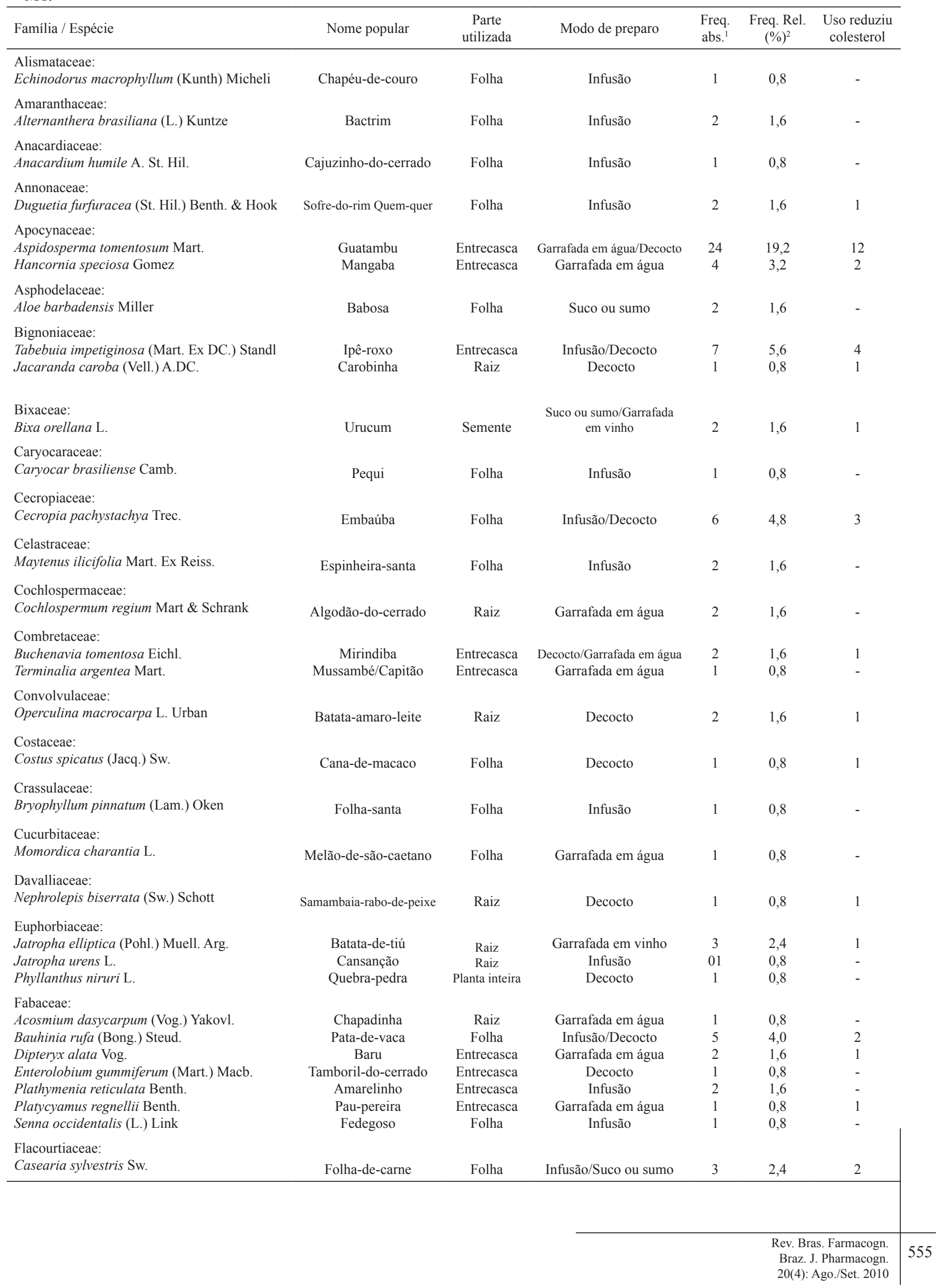


Lauraceae:

Nectandra megapotamica (Spreng.) Mez.

Lecythydaceae:

Lecythis pisonis Camb.

Loganiaceae:

Strychnos pseudoquina St. Hil.

Malpighiaceae:

Byrsonima verbascifolia Rich. Ex A. L. Juss.

Moraceae:

Maclura tinctoria (L.) D. Don ex Steud.

Myrtaceae:

Campomanesia pubescens (DC.) Berg

Eugenia dysenterica Mart. Ex DC.

Syzygium cumini (L.) Skeels

Palmae:

Syagrus oleracea (Mart.) Becc.

Phytolaccaceae:

Petiveria Alliacea L.

Plantaginaceae:

Plantago major L.

Poaceae:

Guadua Weberbaueri Pilger

Polygonaceae:

Triplaris gardneriana Wedd.

Rubiaceae:

Chiococca brachiata Ruiz \& Pav.

Palicourea coriacea (Cham) K. Schum

Rutaceae:

Spiranthera odoratissima A. St.-Hil.

Sapotaceae:

Pouteria ramiflora (Mart.) Radlk.

Scrophulariaceae:

Escobedia grandiflora (L. f.) Kuntze.

Simaroubaceae:

Quassia amara L.

Simaba sp.

Verbenaceae:

Stachytarpheta angustifolia Schrad.

Vitex polygama Cham.

Total

${ }^{1}$ Frequência absoluta / ${ }^{2}$ Frequência relativa em porcentagem

vitro em Plasmodium falciparum (Mesquita et al., 2007).

A quina-do-cerrado (Strychnos pseudoquina

St. Hil.), segunda planta mais citada, foi indicada para

o tratamento de moléstias do estômago, fígado, baço,

cólicas e inflamação, além de ser utilizada como tônica

e afrodisíaca (Rodrigues \& Carvalho, 2001; Souza \&

Felfili, 2006). Esta planta foi eficaz na proteção da mucosa gástrica em camundongos (Silva et al., 2005) e apresentou efeito hipoglicemiante e ausência de efeito cicatrizante em ratos diabéticos por aloxana (Honório-França et al., 2008). O extrato metanólico desta planta, na dose de 100 $\mathrm{mg} / \mathrm{kg}$, reduziu o colesterol sérico em $17 \%$, em modelo de hiperlipidemia induzida em camundongos por Triton WR 1339, atividade esta relacionada ao uso popular de S. pseudoquina em Nova Xavantina (Silva, 2009).

A espécie Tabebuia impetiginosa (Mart. Ex DC.) Standl (ipê-roxo), terceira mais citada em Nova Xavantina, já foi indicada para o tratamento do impetigo (Rodrigues \& Carvalho, 2001). Silva (2006), demonstrou atividades antiinflamatória e antinociceptiva a esta planta. Além disso, alguns de seus compostos isolados mostraram potente atividade em bactéria anti-Helicobacter pylori (Park et al., 2006). No estudo realizado por Silva (2009), Tabebuia impetiginosa também apresentou efeito hipocolesterolêmico em camundongos hiperlipidêmicos por Triton WR 1339, indicando a importância do conhecimento popular verificado em nosso estudo. Outra planta do gênero, a Tabebuia avellanedae, apresentou ação 
antinociceptiva em camundongos (Miranda et al., 2001).

O principal componente ativo de plantas do gênero

Tabebuia é o lapachol, uma quinona, bastante estudada em diversas partes do mundo. Uma revisão completa sobre o lapachol e seus derivados foi realizada por Hussain et al. (2007), onde inúmeras atividades biológicas foram atribuídas a este composto, como antiulcerogênica, leishmanicida, anticarcinogênica, antiedematogênica, antiinflamatória, antimalárica, anti-séptica, antiviral, bactericida, fungicida, pesticida e esquistosomicida.

Segundo os entrevistados, a embaúba (Cecropia pachystachya Trec.), embora possa ser encontrada em outros ambientes, é bastante comum no Cerrado próximo à cidade. Esta planta foi citada como antidiabética (Souza \& Felfili, 2006; Pilla et al., 2006), no tratamento da asma, bronquite, tosse, coqueluche e como diurética (Rodrigues \& Carvalho, 2001). Consolini \& Migliori (2005), atribuíram efeito hipotensor à Cecropia pachystachya, em ratos.

Espécies do gênero Cecropia são encontradas em toda a América do Sul e caracterizam-se por suas propriedades hipoglicemiantes e hipolipidêmicas, como demonstrado em um trabalho mexicano realizado com a espécie Cecropia obtusifolia, onde pacientes foram tratados com esta planta como terapia adicional ao tratamento convencional e obtiveram redução significativa dos níveis de glicose, colesterol e triglicérides em 15,25; 14,62 e 42,0\% respectivamente (Herrera-Arellano et al., 2004). Estudo químico de outra espécie do gênero, a Cecropia glaziovii, evidenciou a presença de catequinas $(12 \%)$, procianidinas $(19 \%)$ e flavonóides $(19 \%)$ em uma quantidade total de $0,5 \mathrm{mg} / \mathrm{mg}$ de extrato aquoso (Tanae et al., 2007).

A família Simaroubaceae possui 32 gêneros com aproximadamente 200 espécies, de distribuição pantropical. Caracterizam-se pela quantidade de substâncias amargas, em sua maioria, responsáveis pelas propriedades farmacológicas atribuídas a essas plantas (Noldin, 2005). São conhecidas por suas propriedades medicinais, no tratamento da malária, como anti-helmínticas e antitumorais (Saraiva et al., 2006).

Plantas do gênero Simaba são representantes muito importantes desta família. Quassinóides de Simaba multiflora e Simaba cuspidata apresentaram atividade antineoplásica (Wani et al., 1978; Polonsky et al., 1980). Estudos demonstraram propriedades antimaláricas de substâncias extraídas de Simaba orinocensis e Simaba guianensis (Cabral et al., 1993; Muhammad et al., 2004).

As folhas de Simaba ferruginea apresentaram o esteróide $\beta$-sitosterol (Noldin, 2005), composto que possui atividade hipocolesterolêmica segundo (Cícero et al., 2004). Essa planta demonstrou efeito antiulcerogênico em diversos modelos animais (Marcello, 2001; Noldin, 2005). Além disso, Simaba ferruginea apresentou toxicidade aguda em teste hipocrático (Marcello, 2001; Barros, 2007; Silva, 2009). Os entrevistados de Nova Xavantina alertaram quanto à toxicidade da calunga, indicando uso em pequenas quantidades e poucas vezes ao dia. As propriedades hipolipidêmicas atribuídas popularmente a plantas do gênero Simaba em nosso estudo, estão de acordo com o trabalho de Silva (2009), onde Simaba ferruginea foi testada em modelos de hiperlipidemia em camundongos, tais como: Triton WR 1339, hipertrigliceridemia por etanol, teste da carga de frutose e indução de hiperlipidemia por dieta rica em gordura, sendo efetiva na redução dos níveis séricos do perfil lipídico dos animais.

$\mathrm{O}$ gênero Bauhinia é caracterizado pela existência de várias substâncias de importância medicinal, como lactonas, flavonóides, terpenóides, esteróides, triterpenos, taninos e quinonas. A medicina popular utiliza espécies deste gênero no combate ao diabetes, e diversos estudos nesta área já foram realizados, sendo que Bauhinia forficata é a espécie que apresenta o maior número de estudos que comprovam sua atividade hipoglicemiante (Silva \& Cechinel Filho, 2002; Pepato et al., 2002; Silva et al., 2002). No entanto, não foram encontrados estudos de constituição química e atividade farmacológica para Bauhinia rufa (Bong.) Steud., uma das plantas mais citadas pelos entrevistados. Portanto, o potencial farmacológico desta planta em hiperlipidemias e obesidade ainda carece de mais estudos.

A mangaba (Hancornia speciosa Gomez) é utilizada no tratamento de moléstias relacionadas ao aparelho genitourinário (Monteles \& Pinheiro, 2007), cólicas menstruais, luxações, hipertensão (Souza \& Felfili, 2006), diabetes, obesidade e dermatoses (Rodrigues \& Carvalho, 2001). O látex desta planta não apresentou atividade antimicrobiana significativa (Santos et al., 2007). Trabalhos voltados às atividades farmacológicas da mangabeira são escassos, portanto, esta planta pode representar boa fonte de pesquisa no combate às hiperlipidemias e à obesidade, visto que foi uma das plantas mais citadas em Nova Xavantina.

O extrato etanólico da planta Jatropha elliptica (Pohl.) Muell. Arg. (batata-de-tiú) apresentou atividade antibacteriana (Lima et al., 2006) e moluscicida (Santos \& Sant'Ana, 1999). Jatropha gossypiifolia reduziu significativamente a pressão sanguínea sistólica em ratos (Abreu et al., 2003). No entanto, nenhum trabalho relacionado às propriedades hipolipidêmicas e anorexígenas de plantas do gênero Jatropha foi encontrado.

A folha de carne (Casearia sylvestris Sw.), também conhecida como erva-de-lagarto e guaçatonga, é utilizada na medicina popular como antidiarréica, antifebril, depurativa, anti-reumática, nas afecções da pele, em mordeduras de cobras, combate a sífilis e cicatrizante (Rodrigues \& Carvalho, 2001; Souza \& Felfili, 2006). Seu óleo essencial foi citotóxico contra linhagens de células tumorais (Silva et al., 2008). $C$. sylvestris também mostrou significante atividade em Leishmania donovani e Trypanosoma cruzi (Mesquita et al., 2005). Contudo, apesar de ser bastante estudada, ainda há carência de estudos que possam comprovar o uso desta espécie no combate às hiperlipidemias e à obesidade. 
O manacá (Spiranthera odoratissima A. St.Hil.) é utilizado popularmente em inflamações uterinas, dor de cabeça, estômago e fígado (Souza \& Felfili, 2006). Folhas do manacá apresentaram atividades analgésica e/ou antiinflamatória segundo estudo de Matos et al. (2003). Ribeiro et al. (2005) isolaram diversas substâncias da raiz de Spiranthera odoratissima: o novo limonóide limonina, os alcaloides dictamina, g-fagarina e esquimianina, os alcaloides rutaecarpina, evodiamina e 1-hidroxirutaecarpina a cumarina aurapteno e $\beta$-sitosterol. No entanto, nenhum artigo relacionado às propriedades hipolipidêmicas e anorexígenas desta planta foi encontrado.

Outro dado importante notado em Nova Xavantina é que os informantes referenciam a dose da planta com a expressão "punhado", ou seja, não existe uma quantidade certa de material vegetal a ser utilizada no preparo. Quanto à posologia, a maioria indicou uso contínuo, sem período determinado de tempo, podendo usar até perceber o resultado. Em estudo realizado por Pilla et al. (2006), também não foi observado rigor na quantidade de material vegetal a ser utilizado, e muitos dos entrevistados não associaram eventuais contra-indicações ao uso de "remédios caseiros". Este autor relata ainda, que boa parte dos usos de plantas é baseada na experiência, reforçando a idéia de que por ser natural não faz mal, fato que considera um equívoco.

Dentre as espécies medicinais citadas, a folha foi a parte mais utilizada (46\%), seguida da entrecasca (28\%) e raiz (18\%). Estes resultados são semelhantes aos de outros estudos (Amorozo, 2002; Pereira et al., 2005; Barreto et al., 2006; Borba \& Macedo, 2006; Pilla et al., 2006; Pinto et al., 2006; Teixeira \& Melo, 2006; Vendruscolo \& Mentz, 2006; Jesus et al., 2009). O maior uso das folhas, provavelmente se deve a facilidade de coleta, ou também a uma consciência de preservar a planta, retirando partes que possam ser repostas não causando danos sérios. Entretanto, deve-se destacar a grande utilização da raiz.

Quanto às formas de uso, infusão ou chá foi o mais citado (36,5\%), seguido da decocção ou fervura $(27 \%)$, garrafada em água $(25,5 \%)$, suco ou sumo $(6 \%)$ e garrafada em vinho (5\%). O preparo da planta na forma de chá também foi bastante citado em outros estudos etnobotânicos (Teixeira \& Melo, 2006; Vendruscolo \& Mentz, 2006; Negrelle et al., 2007; Jesus et al., 2009). Barreto et al. (2006) condenam a fervura da planta por longos períodos, pois essa atividade pode levar a perda dos princípios ativos voláteis, considerando melhor o emprego do infuso para preparação de ervas medicinais.

Tendo em vista o largo emprego popular e os relatos químico-farmacológicos promissores na literatura especializada, quanto às atividades hipolipemiantes, para as plantas dos gêneros Aspidosperma, Strychnos, Simaba e Tabebuia, faz-se necessário a continuidade dos estudos destas espécies, com vista à elucidação do mecanismo de ação e dos compostos responsáveis pelas atividades.

\section{AGRADECIMENTOS}

Aos entrevistados, pela acolhida fraterna e informações valiosas que forneceram aos autores. A Prefeitura Municipal de Nova Xavantina e a Coordenação do Clube da Terceira Idade, pelo auxílio à realização das entrevistas. À Profa. Dra. Maryland Sanches, Coordenadora do Herbário do Iuniaraguaia, pelo auxílio na identificação das espécies coletadas. A Coordenação de Aperfeiçoamento de Pessoal de Nível Superior (CAPES) e ao Centro de Pesquisa do Pantanal (CPP), pelo auxílio financeiro.

\section{REFERÊNCIAS}

Abreu IC, Marinho ASS, Paes AMA, Freire SMF, Olea RSG, Borges MOR, Borges ACR 2003. Hypotensive and vasorelaxant effects of ethanolic extract from Jatropha gossypiifolia L. in rats. Fitoterapia 74: 650-657.

Albuquerque UP, Hanazaki N 2006. As pesquisas etnodirigidas na descoberta de novos fármacos de interesse médico e farmacêutico: fragilidades e perspectivas. Rev Bras Farmacog 16: 678-689.

Amorozo MCM 2002. Uso e diversidade de plantas medicinais em Santo Antonio do Leverger, MT, Brasil. Acta Bot Bras 16: 189-203.

Bahramikia S, Yazdanparast R 2008. Effect of hydroalcoholic extracts of Nasturtium officinale leaves on lipid profile in high-fat diet rats. J Ethnopharmacol 115: 116-121.

Barreto BB, Gomes FV, Teixeira JBP 2006. O uso de plantas medicinais por comunidades carentes no município de Juiz de Fora (MG). XXIX Semana de Biologia e XII Mostra de Produção Científica. Juiz de Fora, Brasil.

Barros WM 2007. Efeito do extrato hidroetanólico dos rizomas da Simaba ferruginea St Hil. (Simaroubaceae), sobre o comportamento e reprodução de ratas da linhagem Wistar. São Paulo, 90 p. Tese de Doutorado, Faculdade de Ciências Médicas, Santa Casa de São Paulo.

Borba AM, Macedo M 2006. Plantas medicinais usadas para a saúde bucal pela comunidade do bairro Santa Cruz, Chapada dos Guimarães, MT, Brasil. Acta Bot Bras 20: 771-782.

Cabral JA, Mcchesney JD, Milhous WK 1993. A new antimalarial quassinoid from Simaba guianensis. J Nat Prod 56: 1954-1961.

Cardozo S, Bona LR, Barboza LT, Andreolla HF, Boeck R, Vieira V, Frantz MA, Morisso FDP, Coitinho AS, Tavares RG 2008. Atividade hipolipidêmica do extrato de Cordia salicifolia em camundongos submetidos a dieta hiperlipidêmica. Revista da AMRIGS 52: 182-186.

Cícero AFG, Minardi M, Mirembe S, Pedro E, Gaddi A 2004. Effects of a new low dose soy protein $/ \beta$-sitosterol association on plasma lipid levels and oxidation. Eur $J$ Nutr 43: 319-322.

Clayton BD, Stock YN 2006. Farmacologia na prática de enfermagem. $13^{\mathrm{a}}$ ed. Rio de Janeiro: Elsevier.

Consolini AE, Migliori GN 2005. Cardiovascular effects of the South American medicinal plant Cecropia pachystachya (ambay) on rats. J Ethnopharmacol 96: 417-422.

Epifânio WAN, Oliveira MP, Melo GMA, Silva SAS, Moreira MSA, Sant'Ana AEG, Araújo Júnior JX 2007. Isolamento de flavonóide das cascas do caule de Aspidosperma tomentosum e atividade analgésica preliminar. $30^{a}$ 
Reunião Anual da Sociedade Brasileira de Química. Águas de Lindóia, Brasil.

Felfili JM, Nogueira PE, Silva Júnior MC, Marimon BS, Delitti WBC 2002. Composição florística e fitossociologia do Cerrado sentido restrito no município de Água Boa-MT. Acta Bot Bras 16: 103-112.

Golan DE, Tashjian Jr. AH, Armstrong EJ, Armstrong AW 2009. Princípios de farmacologia: a base fisiopatológica da farmacoterapia. $2^{\mathrm{a}}$ ed. Rio de Janeiro (RJ): Guanabara Koogan.

Guarim Neto G 1987. Plantas utilizadas na medicina popular do Estado de Mato-Grosso. Brasília. CNPq. Assessoria editorial.

Guarim Neto G, Morais RG 2003. Recursos medicinais de espécies do Cerrado de Mato Grosso: um estudo bibliográfico. Acta Bot Bras 17: 561-584.

Guarim Neto G 2006. O saber tradicional Pantaneiro: as plantas medicinais e a educação ambiental. Rev Eletr Mestrado Edu Amb 17: 71-89.

Harnafi H, Caid HS, Bouanani NH, Aziz M, Amrani S 2008. Hypolipemic activity of polyphenol-rich extracts from Ocimum basilicum in Triton WR-1339-induced hyperlipidemic mice. Food Chem 108: 205-212.

Heerden FR, Horak RM, Maharaj VJ, Vleggaar R, Senabe JV, Gunning PJ 2007. An appetite suppressant from Hoodia species. Phytochemistry 68: 2545-2553.

Herrera-Arellano A, Aguilar-Santamaría L, García-Hernández B, Nicasio-Torres P, Tortoriello J 2004. Clinical trial of Cecropia obtusifolia and Marrubium vulgare leaf extracts on blood glucose and serum lipids in type 2 diabetics. Phytomedicine 11: 561-566.

Honório-França AC, Marins CMF, Boldrini F, França EL 2008. Evaluation of hypoglicemic activity and healing of extract from amongst bark of "Quina do Cerrado" (Strychnos pseudoquina St. HIL). Acta Cir Bras 23: 504-510.

Howard BV, Ruotolo G, Robbins DC 2003. Obesity and dyslipidemia. Endocrinol Metab Clin $N$ Am 32: 855867.

Hussain H, Krohn K, Ahmad VU, Miana GA, Greend IR 2007. Lapachol: an overview. Arkivoc 2: 145-171.

Instituto Brasileiro de Geografia e Estatística (IBGE) 2004. Resultados da amostra do censo demográfico 2000. Malha municipal digital do Brasil: Situação em 2001. Rio de Janeiro (RJ).

Jesus NZT, Lima JCS, Silva RM, Espinosa MM, Martins DTO 2009.Levantamentoetnobotânicodeplantaspopularmente utilizadas como antiúlceras e antiinflamatórias pela comunidade de Pirizal, Nossa Senhora do LivramentoMT, Brasil. Rev Bras Farmacogn 19: 130-139.

Jorge PAR, Neyra LC, Osaki RM, Almeida E, Bragagnolo N 1998. Efeito da berinjela sobre os lípides plasmáticos, a peroxidação lipídica e a reversão da disfunção endotelial na hipercolesterolemia experimental. Arq Bras Cardiol 70: 87-91.

Kidwai AM, Upreti RK 1993. A novel plant membrane proteoglycan which causes anorexia in animals. Mol Cell Biochem 120: 111-117.

Kohn LK, Pizão PE, Foglio MA, Antônio MA, Amaral MCE, Bittric V, Carvalho JE 2006. Antiproliferative activity of crude extract and fractions obtained from Aspidosperma tomentosum Mart. Rev Bras Pl Med 8: 110-115.

Krause MP, Hallage T, Miculis CP, Gama MPR, Silva SG 2008. Análise do perfil lipídico de mulheres idosas em Curitiba
- Paraná. Arq Bras Cardiol 90: 327-332.

Lei F, Zhang XN, Wang W, Xing DM, Xie WD, Su H, Du LJ 2007. Evidence of anti-obesity effects of the pomegranate leaf extract in high-fat diet induced obese mice. Int J Obesity 31: 1023-1029.

Lima MRF, Luna JS, Santos AF, Andrade MCC, Sant'Ana AEG, Genet JP, Marquez B, Neuville L, Moreau N 2006. Antibacterial activity of some Brazilian medicinal plants. $J$ Ethnopharmacol 105: 137-147.

Mansur AP, Mattar APL, Tsubo CE, Simão DT, Yoshi FR, Daci K 2001. Prescription and adherence to statins of patients with coronary artery disease and hypercholesterolemia. Arq Bras Cardiol 76: 115-118.

Marçal AC, Perotti L, Defani MA, Viscovini, RC 2003. Levantamento etnobotânico das plantas medicinais utilizadas pela população de Goioerê-PR. Arq Cienc Saude Unipar 7: 21-26.

Marcello CM 2001. Triagem antiúlcera de plantas medicinais usadas popularmente em Mato Grosso para afecções gastrintestinais e validação pré-clínica de Simaba ferruginea St. Hil (calunga), como antiúlcera. Cuiabá, Dissertação de Mestrado. Instituto de saúde Coletiva, Universidade Federal de Mato Grosso.

Matos FJA 1989. Plantas medicinais - guia de seleção e emprego de plantas usadas em medicina popular no nordeste do Brasil. $1^{\mathrm{a}}$ ed. Fortaleza (CE): IOCE.

Matos LG, Santos LDAR, Vilela CF, Pontes IS, Tresvenzol LMF, Paula JR, Costa EA 2003. Atividades analgésica e/ou antiinflamatória da fração aquosa do extrato etanólico das folhas da Spiranthera odoratissima A. St. Hillaire (manacá). Rev Bras Farmacogn 13: 15-16.

Mesquita ML, Desrivot J, Bories C, Fournet A, Paula JE, Grellier P, Espindola LS 2005. Antileishmanial and trypanocidal activity of Brazilian Cerrado plants. Mem I Oswaldo Cruz 100: 783-787.

Mesquita ML, Grellier P, Mambu L, Paula JE, Espindola LS 2007. In vitro antiplasmodial activity of Brazilian Cerrado plants used as traditional remedies. J Ethnopharmacol 110: 165-170.

Ming M, Guanhua L, Zhanhai Y, Guang C, Xuan Z 2009. Effect of the Lycium barbarum polysaccharides administration on blood lipid metabolism and oxidative stress of mice fed high-fat diet in vivo. Food Chem 113: 872-877.

Ministério da Saúde 1996. Conselho Nacional de Saúde. Resolução 196 de 10 de outubro de 1996. Aprova diretrizes e normas regulamentadoras de pesquisas envolvendo seres humanos. Brasília (DF).

Miranda FGG, Vilar JC, Alves IAN, Cavalcanti SCH, Antoniolli AR 2001. Antinociceptive and antiedematogenic properties and acute toxicity of Tabebuia avellanedae Lor. ex Griseb. inner bark aqueous extract. BMC Pharmacology 1: 1-5.

Monteles R, Pinheiro CUB 2007. Plantas medicinais em um quilombo maranhense: uma perspectiva etnobotânica. Rev Biol Cien Terra 7: 38-48.

Moriguchi EH, Vieira JLC 2006. Dislipidemia em idosos. Envelhecimento e Saúde 12: 24-33.

Muhammad I, Bedir E, Khan SI, Tekwani BL, Khan IA, Takamatsu S, Pelletier J, Walker LA 2004. A new antimalarial quassinoid from Simaba orinocensis. J Nat Prod 67: 772-777.

Murray CDR, Roux CWL, Emmanuel AV, Halket JM, Przyborowska AM, Kamm MA, Murray-Lyon IM 2008. The effect of Khat (Catha edulis) as an appetite suppressant is independent of 
ghrelin and PYY secretion. Appetite 51: 747-750.

Negrelle RRB, Tomazzoni MI, Ceccon MF, Valente TP 2007. Estudo etnobotânico junto à Unidade Saúde da Família Nossa Senhora dos Navegantes: subsídios para o estabelecimento de programa de fitoterápicos na Rede Básica de Saúde do Município de Cascavel (Paraná). Rev Bras Pl Med 9: 6-22.

Noldin VF 2005. Estudo fitoquímico das folhas e rizomas de Simaba ferruginea St. Hil. e avaliação da atividade antiúlcera e antinociceptiva dos extratos e compostos isolados. Itajaí, 91p. Dissertação de Mestrado, Faculdade de Ciências Farmacêuticas, Universidade do Vale do Itajaí.

Oliveira AB, Souza Filho JD, Chiari E, Braga FC, Lombardi JÁ, Abreu e Silva M 2001. Isolamento de alcalóides de Aspidosperma tomentosum biomonitorado por testes in vitro contra Trypanosoma cruzi. III Semana de PósGraduação da UFMG; Belo Horizonte, Brasil.

Park BS, Lee HK, Lee SE, Piao XL, Takeoka GR, Wong RY 2006. Antibacterial activity of Tabebuia impetiginosa Martius ex DC (Taheebo) against Helicobacter pylori. $J$ Ethnopharmacol 105: 255-262.

Pepato MT, Keller EH, Baviera AM, Kettelhut IC, Vendramini RC, Brunetti IL 2002. Anti-diabetic activity of Bauhinia forficata decoction in streptozotocin-diabetic rats. $J$ Ethnopharmacol 81: 191-197.

Pereira G, Aguiar JLP, Moreira L, Bezerra HS 1997. Área e população do Cerrado. Pesq Agrop Bras 32: 1-3.

Pereira CO, Lima EO, Oliveira RAG, Toledo MS, Azevedo AKA, Guerra MF, Pereira RC 2005. Abordagem etnobotânica de plantas medicinais utilizadas em dermatologia na cidade de João Pessoa-Paraíba, Brasil. Rev Bras Pl Med 7: 9-17.

Pilla MAC, Amorozo MCM, Furlan A 2006. Obtenção e uso das plantas medicinais no distrito de Martim Francisco, Município de Mogi-Mirim, SP, Brasil. Acta Bot Bras 20: 789-802.

Pinto EPP, Amorozo MCM, Furlan A 2006. Conhecimento popular sobre plantas medicinais em comunidades rurais de mata atlântica - Itacaré, BA, Brasil. Acta Bot Bras 20: 751-762.

Polonsky J, Varon Z, Moretti C, Pettit GR, Herald CL, Rideout JA 1980. The antineoplastic quassinoids of Simaba cuspidate Spruce and Ailamthus grandis Prain. JNat Prod 43: 503-509.

Prefeitura Municipal de Nova Xavantina. Nossa Cidade. http:// www.portalpublico.com.br/pmnovaxavantina. Acesso em agosto de 2008.

Rang HP, Dale MM, Ritter JM, Flower RJ 2007. Farmacologia. $6^{\mathrm{a}}$ ed. Rio de Janeiro: Elsevier.

Ribeiro TAN, Ndiaye EAS, Velozo ES, Vieira PC, Ellena J, Sousa Júnior PT 2005. Limonoids from Spiranthera odoratissima St. Hil. J Braz Chem Soc 16: 1347-1352.

Ribeiro MN, Vitorino CA, Farias J, Portella A, Braga E, Lenza E 2008. Levantamento florístico e fitossociológico em Cerrado rupestre e Cerrado típico contíguos do parque do bacaba. I Workshop dos Grupos de Pesquisa e da Pós Graduação da Universidade do Estado de Mato Grosso, Cáceres-MT, Brasil.

Rodrigues VEG, Carvalho DA 2001. Levantamento etnobotânico de plantas medicinais no domínio do Cerrado na região do Alto Rio Grande-Minas Gerais. Cienc Agrotec 25: 102-123.

Sano SM, Almeida SP 1998. Cerrado: ambiente e flora. Planaltina (DF): Empresa Brasileira de Pesquisa Agropecuária.
Santos AF, Sant'Ana AEG 1999. Molluscicidal activity of the diterpenoids jatrophone and jatropholones A and B isolated from Jatropha elliptica (Pohl) Muell. Arg Phytother Res 13: 660-664.

Santos SR 2005. Estudo toxicológico pré-clínico do extrato hidroalcoólico da entrecasca do caule de Aspidosperma subincanum Mart. (Guatambu) Cuiabá, Dissertação de Mestrado, Faculdade de Ciências Médicas, Universidade Federal de Mato Grosso.

Santos PO, Barbosa JAM, Melo DLFM, Trindade RC 2007. Investigação da atividade antimicrobiana do látex da mangabeira (Hancornia speciosa Gomes). Rev Bras Pl Med 9: 108-111.

Saraiva RCG, Pinto AC, Nunomura SM, Pohlit AM 2006. Triterpenos e alcalóide tipo cantinona dos galhos de Simaba polyphylla (Cavalcante) W.W. Thomas (Simaroubaceae). Quim Nova 29: 264-268.

Seplan 2007. Secretaria de Estado de Planejamento de Mato Grosso. Anuário Estatístico de Mato-Grosso-2007 29: Cuiabá. Seplan-MT.

Silva KL, Cechinel Filho V 2002. Plantas do gênero Bauhinia: composição química e potencial farmacológico. Quim Nova 25: 449-454.

Silva FRMB, Szpoganicz B, Pizzolatti MG, Willrich MAV, Sousa E 2002. Acute effect of Bauhinia forficata on serum glucose levels in normal and alloxan-induced diabetic rats. J Ethnopharmacol 83: 33-37.

Silva MA, Rafacho BPM, Hiruma-Lima CA, Rocha LRM, Santos LC, Sannomiy AM 2005. Evaluation of Strychnos pseudoquina St. Hil. leaves extract on gastrointestinal activity in mice. Chem Pharm Bull 53: 881-885.

Silva IEF 2006. Obtenção e avaliação da atividade analgésica e antiinflamatória de extratos hidroalcoólicos de casca, folhas e flores de Tabebuia impetiginosa (Mart. ex DC) ipê-roxo. Franca, 81p. Dissertação de mestrado, Mestrado em Promoção de Saúde, Universidade de Franca.

Silva EF, Santos TRR, Bulhão CF 2007. Levantamento florístico das lianas lenhosas, arbustos e subarbustos do Cerrado do Parque do Bacaba, Nova Xavantina - MT. Rev Bras Biocienc 5: 948-950.

Silva SL, Chaar JS, Figueiredo PMS, Yano T 2008. Cytotoxic evaluation of essential oil from Casearia sylvestris Sw on human cancer cells and erythrocytes. Acta Amaz 38: 107-112.

Silva MAB 2009. Levantamento etnobotânico e triagem hipolipidêmica de plantas medicinais do Cerrado matogrossense: avaliação da atividade hipolipidêmica da Simaba ferruginea St. Hil. e Vochysia rufa Mart. Cuiabá, 166p. Dissertação de mestrado, Faculdade de Ciências Médicas, Universidade Federal de mato Grosso.

Sociedade Brasileira de Cardiologia 2002. Diretrizes sobre obesidade. Arq Bras Cardiol 78

Souza CD, Felfili JM 2006. Uso de plantas medicinais na região de Alto Paraíso de Goiás, GO, Brasil. Acta Bot Bras 20: 135-142.

Tanae MM, Lima-Landman MTR, Lima TCM, Souccar C, Lapa AJ 2007. Chemical standardization of the aqueous extract of Cecropia glaziovii Sneth endowed with antihypertensive, bronchodilator, antiacid secretion and antidepressant-like activities. Phytomedicine 14: 309-313.

Teixeira AS, Melo JIM 2006. Plantas medicinais utilizadas no município de Jupi, Pernambuco, Brasil. Iheringia 61: 5-11. 
Tresvenzol LMF, Paula JR, Ribeiro AF, Ferreira HD 1997. Levantamento das plantas medicinais do estado de Goiás. IV Encontro de Pesquisadores da UFG; Goiânia, Brasil.

Turolla MSR, Nascimento ES 2006. Informações toxicológicas de alguns fitoterápicos utilizados no Brasil. Rev Bras Ciênc Farm 42: 289-306.

Vacanti LJ, Santos SCM, Fujita AM, Lima DS, Lopes AF, Vetorazi R, Sellera A, Scarin NR 2005. A baixa taxa de obtenção da meta do LDL - colesterol numa população de baixa renda. Arq Bras Cardiol 85: 162-165.

Vendruscolo GS, Mentz LA 2006. Levantamento etnobotânico das plantas utilizadas como medicinais por moradores do bairro Ponta Grossa, Porto Alegre, Rio Grande do Sul, Brasil. Iheringia 61: 83-103.

Vieira RF, Martins MVM 1996. Estudos etnobotânicos de espécies medicinais de uso popular no Cerrado. VIII Simpósio sobre o Cerrado; Brasília, Brasil.

Wani MC, Taylor HL, Thompson JB, Wall ME 1978. Plant antitumoragents XVI6alpha-Senecioyloxy-chaparrinone, a new antileukemic quassinoid from Simaba multiflora. Lloydia 41: 578-583.

Xie W, Wang W, Su H, Xing D, Cai G, Du L 2007. Hypolipidemic mechanisms of Ananas comosus L. leaves in mice: different from fibrates but similar to statins. J Pharmacol Sci 103: 267-274. 
Anexo 01 - Questionário utilizado para coleta das informações.

$\mathrm{N}^{\circ}:$

DATA

\section{ENTREVISTADOR:}

- Dados Pessoais:

Idade:

Escolaridade:
a) ( ) Analfabeto
b) ( ) Ens. Fundamental Incompleto
c) ( ) Ens. Médio Incompleto
e) ( ) Apenas Alfabetizado
d) ( ) Superior Incompleto
f) ( ) Ens. Fundamental Completo
g) ( ) Ens. Médio Completo
h) ( ) Superior Completo

- Dados sobre o uso de plantas medicinais:

1) Utiliza regularmente plantas medicinais para tratamento de alguma doença?
( ) $\mathrm{Sim}$
( ) Não (ir para questão 8, perguntar se conhece)

2) Quem mais lhe influenciou a usar plantas medicinais?

a) ( ) Pai b) ( ) Mãe c)( )Avós d)( )Tios e)( )Cônjuge f)( )Amigos g)( ) Outros

3) No geral, o que você acha do efeito das plantas?
( ) Fraco
( ) Moderado
( ) Acentuado

4) Você acha que as plantas são mais eficazes que os remédios de farmácia?
( ) $\mathrm{Sim}$
( ) Não

5) Aconselha os mais jovens a usar plantas medicinais?
( ) $\operatorname{Sim}$
( ) Não

6) Já sentiu algum mal estar (efeito adverso) após o uso de alguma planta medicinal?

$\begin{array}{lll}\text { ( ) Sim: Planta_ } & \text { Efeito_ } & \text { Efeito_ Não } \\ \text { Planta_ } & & \end{array}$

7) Sua taxa de gordura no sangue (colesterol ou triglicérides) estava aumentada (acima do limite considerado normal) no último exame? ( ) $\operatorname{Sim}$ ( ) Não (ir para questão 8, perguntar se conhece)

8) Você usa, já usou, conhece ou ouviu falar a respeito de alguma planta encontrada no Cerrado da região e utilizada para diminuir a gordura do sangue (colesterol, triglicérides) ou emagrecer?
( ) $\operatorname{Sim}$ (Listar Abaixo)
( ) Não (Encerrar)

Planta (Nome Popular):

Parte Utilizada:
( ) Entrecasca do caule
( ) Casca da Raiz
( ) Folha
( ) Flor
( ) Semente
( ) Fruto
( ) Raiz
( ) Planta Inteira
( ) Látex

( ) Outras:

Modo de Preparo:
( ) Infusão ou chá
( ) Garrafada em água (maceração)
( ) Decocto ou fervura
( ) Suco ou sumo
( ) Outras:
( ) Garrafada em vinho (maceração)

Onde encontrar:

Alguma recomendação especial para coleta e preparo (época do ano, cuidados, etc.):

Dosagem (Descrever o que a pessoa falar: quantidade de folhas, partes do fruto, tamanho mais ou menos da raiz, etc.):

Posologia (quantas vezes ao dia e durante quanto tempo)

Reduziu o colesterol (caso a pessoa tenha usado):

( ) $\operatorname{Sim}$ ( ) Não 